\title{
Design and Development of Forest Fire Detecting Drone
}

\author{
P.Aruna Jeyanthy, S.Balasubramanian, R.Balavignesh, P.AzaghuPandi
}

\begin{abstract}
The proposed research work describes a novel fire detecting drone for forest fires. The fire detecting drone helps the fire rescue officers to detect the fire and navigate it. The normal drone is in general high cost and complicated to operate. The proposed drone designed and developed in this work is economical and simple in operation. The weight of the novel drone is also comparatively less than the normal drone. Thermal imaging camera detects the fire and transmits the data to the rescue officer. GPS module sent the exact location of the fired place to the officer. The viewing angle of normal drone camera is about $50^{\circ}$. But the proposed drone provides up to $170^{\circ}$ wide angle. When the drone fly's over the fired area, the camera streams the live situation of the fired to the smart phone through Wi-Fi. Then the location of the affected area is transmitted to the smart phone through GPS module. Then the drone drop $\mathrm{CO}_{2}$ bomb on the fire, which reduce the fire spreading. Then the rescue squad takes charge for the final fire extinguishing.
\end{abstract}

Keywords-Flight controller, ESC, GPS module, Action camera, Transmitter, Receiver

\section{INTRODUCTION}

The aim of the work is to design and develop a drone for fire rescue officers. In the time of forest fire rescue operation, it is difficult to enter inside with fire engine. So the helicopters are used to rescue all from the severity of fire operation. But on the top view, more and more smoke made the rescue operation more difficult. The rescue helicopter could not find the exact fired location. It takes some timeand it slow up the process. This state of condition will increases the damage level. So the researchers have spent decades to develop an Unmanned Aerial Vehicle (UAV) called drone to make the rescue process safe and fast. The drone can enter into the fired area easily and it detects the fire using thermal imaging camera and transmits the data and location to the rescue officer. But the weight, cost and the complexity exists in handling the existing system. To overcome the existing problems the novel drone is developed.
Revised Manuscript Received on December 05, 2019.

P.Aruna Jeyanthy, EEE dept KARE Krishnankoil, India.

S.Balasubramanian, EEE dept KARE Krishnankoil, India. $A$ b.subramanian741@gmail.com

R.Balavignesh, EEE dept KARE Krishnankoil, India balatuw@ gmail.com. $B$.

P.AzaghuPandi, EEE dept KARE Krishnankoil, IndiaC.

azhagupandi24011999@gmail.com

\section{LITERATURE SURVEY}

The inclusions of interface devices namely the personal computers, mobile phones e.t.c are have the computational and communication capabilities in the distribution processing system. These computational capabilities are meant for interfacing the work so as to do the processing without lumped[1-3]. Recently UAV gains importance due to its potentiality in performing the task independently. Tedious and complex works starting from identification to monitoring and protection can be performed successfully. Development of the single UAV is first designed and later the UAVs with above complex collaborating functions were designed [4-7]. Implementations of these UAVs are carried out plenty so far in the distributed processing systems [8]. In this paper we also survey the applications implemented over cooperative teams of UAVs that operate as distributed processing systems.

\section{DESCRIPTION OF THE PROPOSED WORK}

Figure1 represents the schematic diagram of the drone available at present in the market sale. The hardware demonstration for the proposed work is given below: In order to avoid the damages and the massive destruction accidently occurs due to the forest fire, the design of the drone is carried out in this work with less weight and less cost. The complexities and the rescue work by using the existing drone is well understood in the given authors [811]. Hence, in this research, a simplified drone with the available components are deigned to overcome the drawbacks mentioned in the above literature. The above work can also be extended as a monitoring and protective aerial movable vehicle for other applications. The description of the work is stated with the components and the methodology.

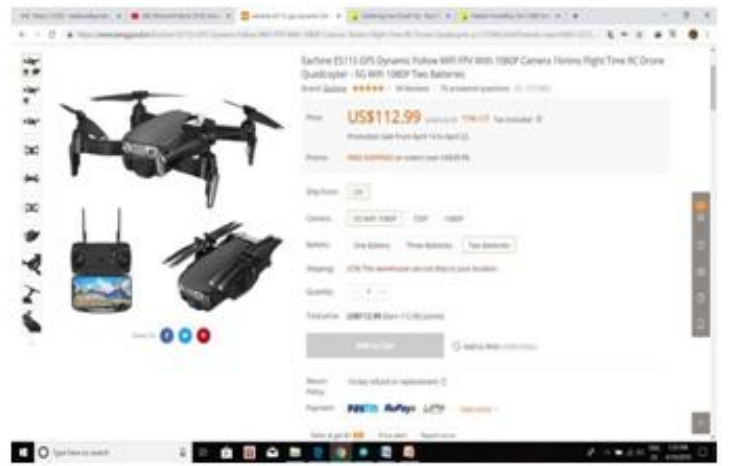

Figure 1 : Existing drone in market 


\section{Components description}

The components which are used in this work are namely;

1. Electronic Speed controller

2. Multi rotor flight controller

3. Brushless DC motor

4. Lipo battery

5. Transmitter

6. Receiver

7.Propeller

8. Thermal imaging camera

9. Monitor

10. Carbon bomb

11. GPS module

E. Methodology

The proposed system that implemented is according to the figure 2. It consists of Multi rotor flight controller, Electronic speed controller, Brushless dc motors, transmitter and receivers and the other accessories for assembling the components for the design and development of the work. During forest fire, it is difficult to enter inside with fire engine. So the rescue helicopters are used. But on the top view, more and more smoke made the rescue operation more difficult. The rescue helicopter could not find the exact fired location. It takes some time and it slow up the process. This condition increases this damage level. So we use UAV, which means Unmanned Aerial Vehicle (Drone) to make the rescue process safe and fast. The drone can enter into the fired area easily and it detects the fire and transmits the data and location to the rescue officer. The transmitter transmits the signal to the receiver. The receiver is connected to the flight controller.

The receiver delivers the data to the flight controller. The flight controller passes the data to the Electronic Speed Controller (ESC).ESC modulates the motor speed. When the drone fly's over the fired area, the camera streams the live situation of the fired to the smart phone through Wi- Fi. Then the location of the affected area is transmitted to the smart phone through GPS module.

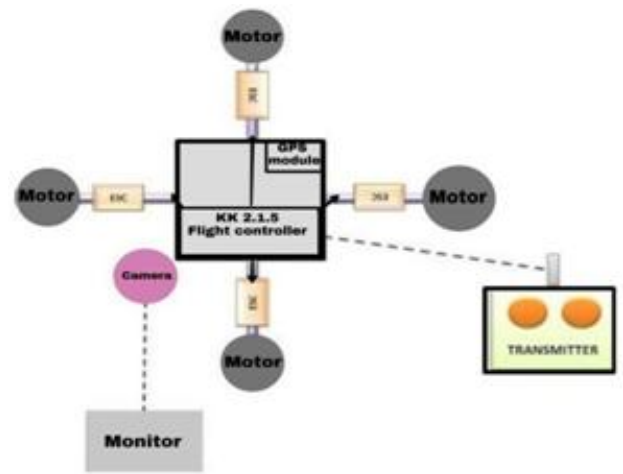

Figure 2 Block diagram of the proposed work

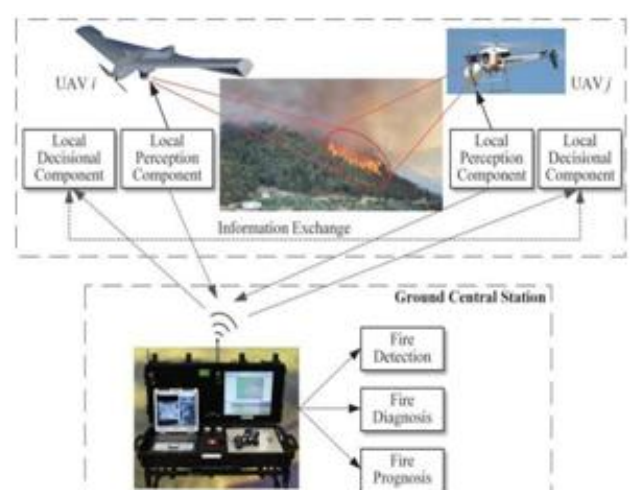

Figure 3: Design circuit of the proposed drone

After the thermal camera detects the fire, the operator makes the drone to drop the $\mathrm{CO}_{2}$ bomb on the fire, which reduce the fire spreading. Then the rescue squad take charge. The detailed operation is represented in the Figure 3. The main advantages of the novel drone is given as a comparison table in the Table 1 stated below.

\begin{tabular}{|l|l|l|}
\hline \multirow{2}{*}{ S.No } & \multicolumn{2}{|c|}{ Forest Fire Drone } \\
\cline { 2 - 3 } & \multicolumn{1}{|c|}{ Existing } & \multicolumn{1}{c|}{ Proposed } \\
\hline 1 & $\begin{array}{l}\text { Not Economical (Cost price is } \\
\text { Rs.27,000/- to 70,000/-) }\end{array}$ & $\begin{array}{c}\text { Economical(Cost price is } \\
\text { approximately Rs. } \\
14,000 /-\end{array}$ \\
\hline 2 & $\begin{array}{l}\text { Battery withstanding capacity is } \\
\text { low (only 3 hours) }\end{array}$ & $\begin{array}{l}\text { Battery withstanding } \\
\text { capacity is high (more }\end{array}$ \\
\hline
\end{tabular}

TABLE I.

COMPARISON STUDY WITH THE EXISTING PRODUCT

\begin{tabular}{|l|l|l|}
\hline \multirow{2}{*}{ S.No } & \multicolumn{2}{|c|}{ Forest Fire Drone } \\
\cline { 2 - 3 } & \multicolumn{1}{|c|}{ Existing } & \multicolumn{1}{|c|}{ Proposed } \\
\hline \multirow{2}{*}{ than 3 hours) } \\
\hline 3 & $\begin{array}{l}\text { Viewing angle camera is about } \\
50^{0}\end{array}$ & $\begin{array}{l}\text { Viewing angle camera } \\
\text { is up to } 170^{\circ}\end{array}$ \\
\hline 4 & Heavy & Less in weight \\
\hline 5 & $\begin{array}{l}\text { Complicated in handling and } \\
\text { operation }\end{array}$ & Simple \\
\hline
\end{tabular}

\section{IV.CONCLUSION}

Thus, the novel design of forest fire drone is developed. The developed hardware is ready to introduce in the market for the betterment of the Fire rescue officers, farmers, land owners, people residing in the nearby the forest areas, estate worker as a prototype protective device for their day to day use.

\section{REFERENCES}

1. Zydek, D., Chmaj, G., Chiu, S.: Modeling Computational Limitations in H-Phy and Over- lay-NoC Architectures, The Journal of Supercomputing. (2013) doi: 10.1007/s11227-013-0932-9

2. Baker, M., Buyya, R., Laforenza, D.: Grids and Grid technologies for wide-area distributed computing, Software: Practice and Experience, vol. 32, Issue 15, pp. 1437-1466.(2002)

3. Chmaj, G., Walkowiak, K.: Decision Strategies for a P2P Computing System, Journal of Universal Computer Science, vol. 18, no. 5, pp. 599-622. (2012), doi: 10.3217/jucs-018-05-0599

4. Wada Akihisa, Yamashita Toshiaki, Maruyama Masaaki, Arai Takanari, Adachi Hideo, Tsuji Hirokazu,: A Surveillance System Using Small Unmanned Aerial Vehicle (UAV) Re-lated 
Technologies, Special Issue on Solving Social Issues Through Business Activities, NEC Technical Journal, Vol.8, No.1. (2013)

5. Mayerowitz, S.: Amazon.com sees delivery drones as future, Phys.org, The Associated Press, 2013

6. Winnefeld, J.A., Kendall, F.: Unmanned Systems Integrated Roadmap FY2013-2038, Department of defence , 14-S-0553, DIANEE publishing companay 2014

7. Long, M., Gage, A., Murphy, R., Valavanis, K.: Application of the Distributed Field Robot Architecture to a Simulated Demining Task, Proceedings of the 2005 IEEE International Conference on Robotics and Automation, pp. 31933200(2005),doi: 10.1109/ROBOT.2005.1570602

8. Ryan, A., Xiao, X., Rathinam, S., Tisdale, J., Zennaro, M., Caveney, D., Sengupta, R., Hedrick, J.K.: A Modular Software Infrastructure for Distributed Control of Collaborating UAVs, Proceedings of the AIAA Conference on Guidance, Navigation and Control, (2006)

9. Abdalhaq, B., Cortes, A., Margalef, T., and Luque, E. 2005. Enhancing wild land fire prediction on cluster systems applying evolutionary optimization techniques. Future Generation Comp. Syst. 21(1): 61-67. doi:10.1016/j.future.2004.

10. Alexis, K., Nikolakopoulos, G., Tzes, A., and Dritsas, L. 2009 Coordination of helicopter UAVs for aerial forest-fire surveillance. In Applications of intelligent control to engineering systems.Springer , Netherlands,pp.169-193.

11. Alonso-Betanzos, A., Fontenla-Romero, O., Guijarro-Berdinas, B., Hernandez-Pereira, E., Andrade, M.I.P., Jimenez, E., Soto, J.L.L., and Carballas, T. 2003. An intelligent system for forest fire risk prediction and firefighting management in Galicia. 